\title{
THE PRODUCTION AND PHENOTYPES OF WHEAT-RYE CHROMOSOME ADDITION LINES
}

\author{
RALPH RILEY and VICTOR CHAPMAN \\ Plant Breeding Institute, Cambridge
}

Received 7.x.57

\section{INTRODUCTION}

I $\mathrm{T}$ is impossible to transfer characteristics of rye, Secale cereale a diploid, to wheat, Triticum vulgare a hexaploid, by normal breeding methods since there is very rarely, if ever, any meiotic pairing between the chromosomes of the two species in the intergeneric hybrid. This has been particularly tantalising to plant breeders because there are characters of rye which it would be economically valuable to incorporate in wheat. Consequently the amphidiploids derived from wheat-rye hybrids by chromosome doubling have attracted considerable attention (Rimpau, I89I; Lindschau and Oehler, I935; Müntzing, I939 and I948; Riley and Chapman, I957), since in these plants the complete gene-complements of wheat and of rye are associated in fertile combinations. However, because of their low fertility and the genetic antagonism of the parental genotypes, wheatrye amphidiploids have been of no value in agriculture. Analogous amphidiploids between wheat and related primitive species in the genus Egilops are similarly of no direct value (Bell, Lupton and Riley, 1955) because disadvantageous features of the primitive species are included together with the desired characters.

It was proposed by O'Mara (I940) that the undesirable features of wheat-rye and other amphidiploids might be overcome by incorporating with the wheat genotype not the whole genome of another species but the smallest part of the genome which was necessary in order to introduce the desired character. There would then be the minimum alteration of the basic phenotype of the wheat. For a character, controlled by a single gene, to be introduced from a species such as rye, the chromosomes of which are not homologous with those of wheat, the problem resolves itself into the transfer to wheat of a single pair of alien chromosomes. It was proposed that the alien pair should be added to the full complement of wheat chromosomes to produce what R. E. Clausen (Gerstel, 1945) has referred to, in Nicotiana, as an "alien addition" line. Because of their balanced chromosome constitutions such lines might be expected to be true-breeding and of normal fertility.

O'Mara (I940 and I95I) successfully demonstrated that by a sequence of manipulations in which the wheat-rye amphidiploid was crossed with wheat and the derivatives allowed to self for one or more generations it was possible to obtain plants which had the full 
complement of wheat chromosomes plus rye chromosome I, monosomic or disomic. Subsequently Chapman and Riley (I955) have obtained the disomic addition of rye chromosome II to wheat, using essentially the same technique as O'Mara.

Techniques differing from O'Mara's have been used by Hyde (1953) to add five of the chromosomes of Haynaldia villosa to wheat, by Sears (1956) to add a chromosome of Agilops umbellulata to wheat, and by Gerstel (I945) to make chromosome transfers between species of Nicotiana.

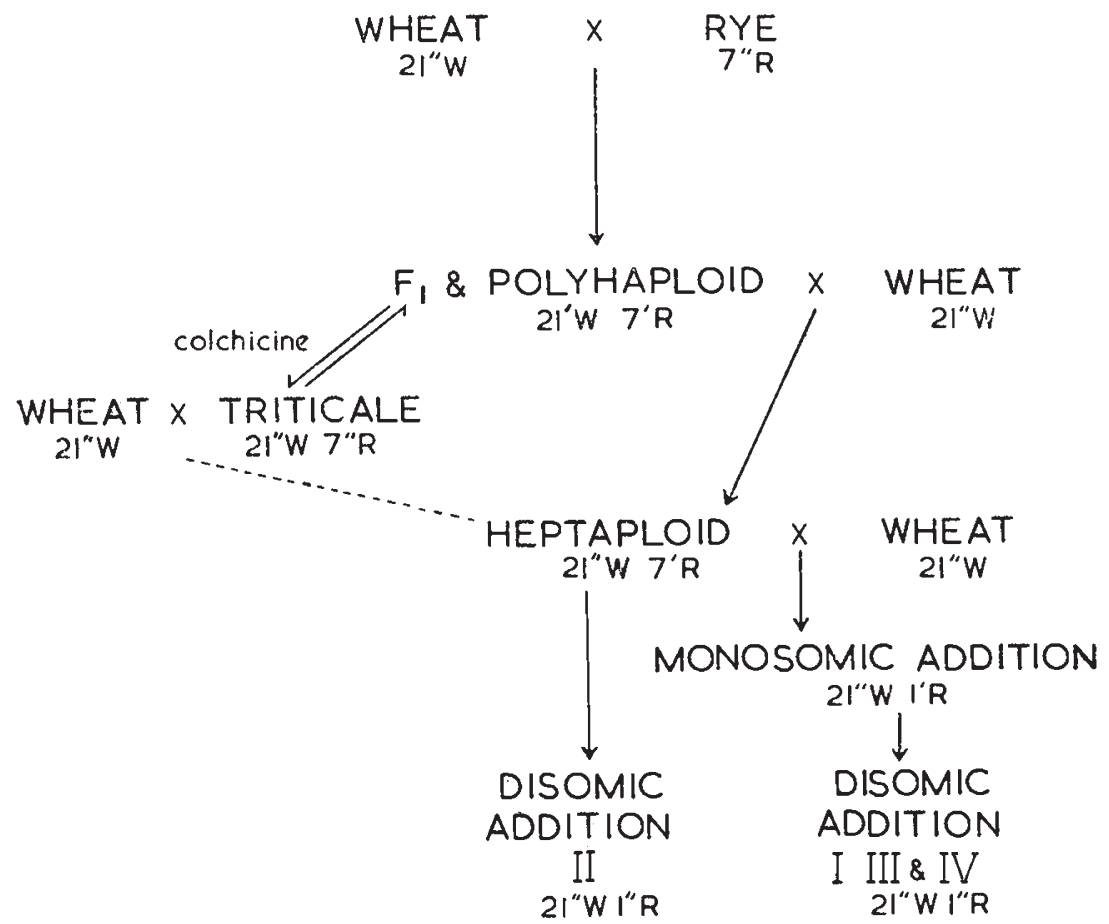

TEXT-FIG. 1.-The breeding technique illustrated was used to extract plants with pairs of rye chromosomes separately added to the full complement of wheat chromosomes. The present addition lines, shown by roman numerals at the disomic addition level, were obtained by the sequence marked with continuous lines between generations. Subsequent work was based on crossing the wheat-rye amphidiploid with wheat to obtain heptaploids, as indicated by the dotted line. $(W=$ wheat and $R=$ rye chromosomes, "= bivalents and '= univalents at meiosis.)

The transfer of individual pairs of chromosomes from one species to another is thus possible, at least in some groups, and it is apparent that the technique may not only be of value in plant breeding but that it also permits the creation of novel situations of cytogenetic interest. For in material of this type each chromosome pair of the donor species can be isolated from the rest of the complement and examined separately against the genotypic background of the recipient species. It may thus be possible to determine the linkage groups of genes the expressions of which are epistatic to those of the recipient species, or which interact with genes of the recipient species. Since 
the added chromosome will sometimes be morphologically recognisable, particular genes may be related to particular chromosomes, a task which is difficult using euploids. Also, as with the study of chromosome races within species, such as trisomics (Blakeslee and Avery, I934; Blakeslee, I934) and monosomics (Sears, 1954), genes may be located which are inaccessible to formal genetic study since only one allele is known. Further, the behaviour of chromosome pairs transferred to a foreign genotypic background is of cytogenetic and evolutionary interest.

It was for both practical and theoretical reasons, therefore, that the present studies on the transfer of individual chromosomes from rye to wheat were undertaken. The present paper is concerned with the production and phenotypes of lines in which single rye chromosomes, or pairs of chromosomes, have been separately added to the full complement of wheat chromosomes.

\section{MATERIALS AND METHODS}

The two species concerned in the present chromosome manipulations are :Secale cereale L. strain King II $(2 n=14)$.

Triticum vulgare Vill. variety Holdfast (= Triticum astivum L. emend, Fiori and Paoletti) $(2 n=42)$.

Meiotic examinations were made on permanent Feulgen squashes of pollen mother cells, in which 1 per cent. orcein in 45 per cent. propionic acid was used for the final squash instead of the usual 45 per cent. acetic acid. Root-tips for chromosome counting were similarly stained after being pre-treated in $\alpha$-bromonaphthalene.

\section{THE PRODUCTION OF ADDITION LINES}

The method used to obtain addition lines deviated somewhat from that proposed by O'Mara (1940) since in the present work a 28 chromosome polyhaploid, which arose in the amphidiploid derived from Holdfast and King II, was crossed with Holdfast (fig. I). This polyhaploid plant was like the species-hybrid in phenotype and in the frequency of bivalents at meiosis, and very probably combined the haploid complements of wheat and rye.

One plant was derived from the cross between the polyhaploid and Holdfast wheat, and this was a heptaploid with 49 chromosomes. Since 2 I of the chromosomes of the heptaploid were received from the wheat parent an unreduced gamete with the full set of 28 chromosomes must have been received from the polyhaploid. At meiosis the chromosomes from the wheat parent paired with 21 of the chromosomes from the polyhaploid, and seven of the chromosomes from the polyhaploid remained as univalents. This plant then had the full complement of 42 wheat chromosomes and the haploid set of seven rye chromosomes.

This diagnosis of the constitution of the heptaploid was confirmed by the behaviour of two 42 -chromosome plants obtained by crossing it with Holdfast, for at meiosis these derivatives had 2 I bivalents, and were phenotypically similar to Holdfast. These plants had 
returned to the chromosome constitution of wheat, and since the 2 I chromosomes they had received from the heptaploid must have been involved in bivalents in that parent the bivalents are shown to have been composed of wheat chromosomes, and the univalents of rye chromosomes.

The seven rye univalents in the 49-chromosome plant were included in the gametes, or excluded, at random, so that when it was crossed again to wheat, or allowed to self, 25 aneuploids with chromosome numbers ranging from $4^{2}$ to $5^{2}$ were obtained. The two 42 -chromosome derivatives have been discussed above and only the $43^{-}$and 44-chromosome forms from which addition lines were developed have here been considered further.

Seven of the plants derived from the heptaploid had 43 chromosomes which formed 2 I bivalents and one univalent at meiosis. There were three readily distinguishable phenotypic categories, and the lines developed from these plants have confirmed the distinctiveness of the classes. These 43 -chromosome plants were monosomic for the addition of one or other of three rye chromosomes to the full complement of wheat. Subsequently the 43 -chromosome plants were allowed to self and amongst their progenies were small proportions of individuals with 44 chromosomes which made 22 bivalents at meiosis. In each case, therefore, the added rye chromosome had been obtained as a disomic addition to the full wheat complement, and this condition was to varying extents stable from generation to generation. Three of the addition lines, described below, were derived from the initial monosomic addition plants.

The other addition line extracted from this material was obtained directly as a 44-chromosome disomic addition of rye chromosome II, as a result of selfing the heptaploid plant.

Four distinct rye chromosome addition lines, of the seven possible, were thus established from the first or second generation derivatives of the original heptaploid plant. Disomic additions of each chromosome were crossed together to test their distinctiveness and the formation of 2 I bivalents and two univalents in the interline hybrids confirmed that a different rye chromosome had been added in each case. Disomic additions of each line were crossed with Holdfast wheat and in the 43-chromosome $F_{1}$ 's 2 I normal bivalents and one univalent were formed. This confirms that the wheat chromosome complement remained intact and structurally undisturbed in the addition lines, and that an alien pair of chromosomes had indeed been added.

\section{THE PHENOTYPES OF THE ADDITION LINES}

In the following descriptions of the phenotypes of the addition lines the only characters that have been considered are those which are altered in the addition lines compared with Holdfast, the wheat parent (table I). Attention has therefore been concentrated on the 


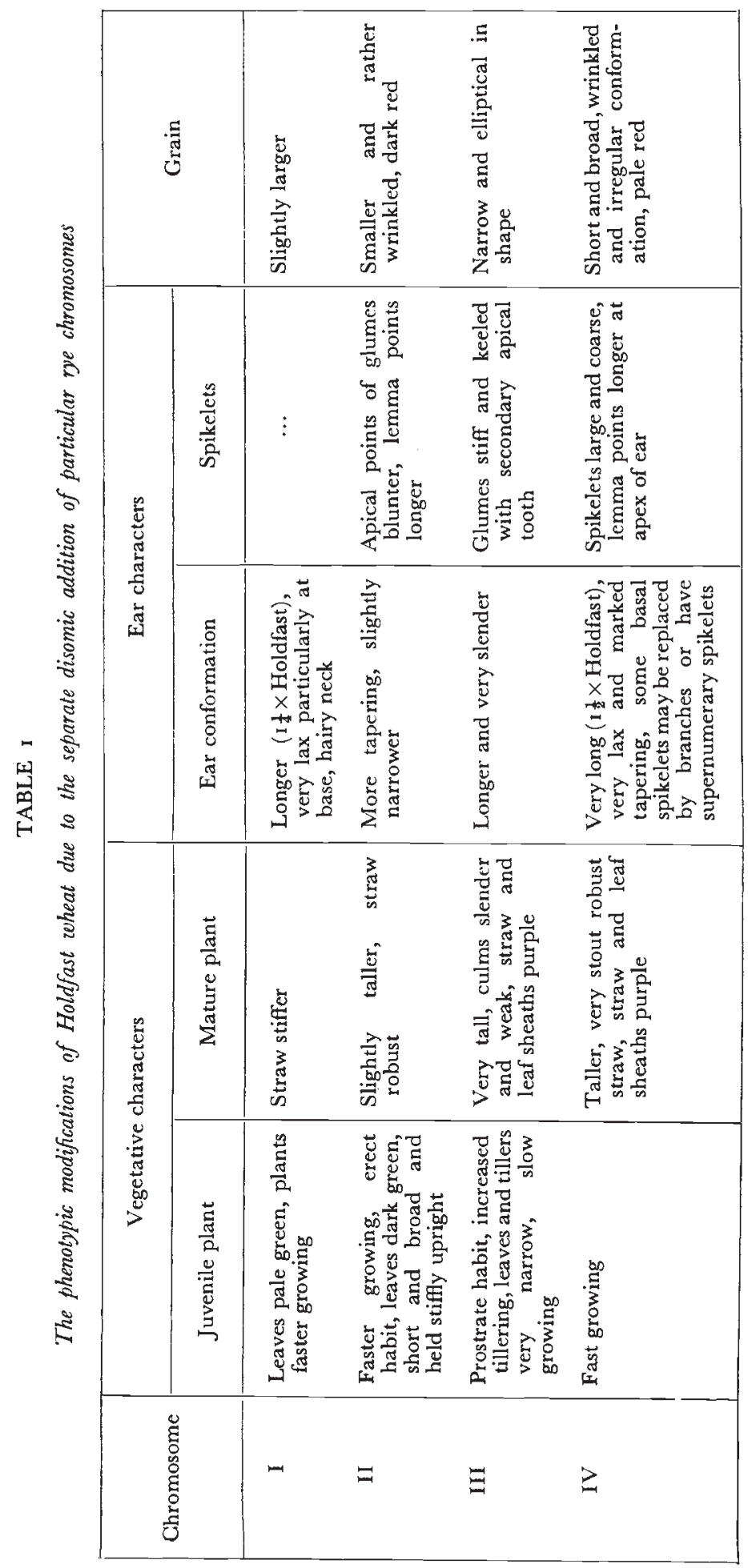


influence of the rye chromosomes in modifying the phenotype of wheat, and to indicate the possibilities from the direct introduction

TABLE 2

The characters in which King II rye is distinct from Holdfast wheat

\begin{tabular}{|c|c|c|c|c|}
\hline & & & & Characters in King II * \\
\hline Leaves & . & - & & $\begin{array}{l}\text { Broader and darker green with auricles which are smaller } \\
\text { and not hairy }\end{array}$ \\
\hline Stem & . & - & • & $\begin{array}{l}\text { Plants are taller, peduncles pubescent (" hairy neck"), straw } \\
\text { purple at maturity }\end{array}$ \\
\hline Ears & & . & • & Longer, denser, more tapering from base to apex \\
\hline Apical sp & jikelet & & . & No apical spikelet differentiated in morphology and orientation \\
\hline Spikelets & & . & . & 2 , rarely 3 , florets fertile in each spikelet ( 4 in Holdfast) \\
\hline Glumes & & . & . & $\begin{array}{l}\text { Very narrow, acutely tapering, one nerve (broad, abruptly } \\
\text { shouldered and with several nerves in Holdfast) }\end{array}$ \\
\hline Lemmas & . & & • & $\begin{array}{l}\text { Broader than glumes, long and tapering acutely to form an } \\
\text { awn, distinctly keeled and the keel fringed with hairs }\end{array}$ \\
\hline Grains & . & & • & $\begin{array}{l}\text { Exposed in the ear at maturity, long and elliptical in shape, } \\
\text { grey in colour (short, oval and white in Holdfast) }\end{array}$ \\
\hline Diseases & . & - & . & $\begin{array}{l}\text { Susceptible to rye races and immune to wheat races of brown } \\
\text { rust and mildew; immune to wheat races of yellow and } \\
\text { stem rust }\end{array}$ \\
\hline
\end{tabular}

* The expressions of the characters listed are in direct contrast to those in Holdfast except in descriptions where Holdfast is also described.

of rye characters the distinctions between Holdfast and King II are listed in table 2. Plants with the rye chromosomes disomic have been principally examined; monosomics have only been considered where they differ from disomics (table 3 ).

TABLE 3

The phenotypic differences of monosomic from disomic additions of particular rye chromosomes to Holdfast wheat

\begin{tabular}{|c|c|c|c|c|}
\hline \multicolumn{4}{|c|}{ Chromosome } & Differences in monosomics \\
\hline $\begin{array}{l}\text { II. } \\
\text { III. } \\
\text { IV. }\end{array}$ & . & $\dot{\bullet}$ & - & $\begin{array}{l}\text { Leaves narrower and longer, not so erect in habit, not so fast } \\
\text { growing, taller at maturity. Not so resistant to mildew } \\
\text { Leaves and culms broader, fewer tillers, ears broader and } \\
\text { much more fertile } \\
\text { No branched ears or supernumerary spikelets }\end{array}$ \\
\hline
\end{tabular}

The descriptions have been based on plants grown in the greenhouse, although material grown in the field was also examined. All qualitative differences were equally obvious whether the plants were from the field or greenhouse, but some of the quantitative differences were less distinct in the field. About 20 plants of each addition line were examined each year for three years, covering three generations, in the greenhouse, and a further 40 plants of each line were examined for each of two years, covering two generations, in the field. Juvenile and mature plants and ear specimens are illustrated in plate I. 
The descriptions of the ears of the addition plants are based on the examination of fully ripe material. The information on disease resistance (table 4) is based on artificial infections of seedlings made by $\mathrm{Dr}$ R. G. F. Macer, which will be described in detail elsewhere, and observations of natural infections in the field. The pathogens used in these tests were: one wheat isolate and one rye isolate of mildew (Erysiphe graminis), one wheat race of yellow rust (Puccinia glumarum), one isolate of rye brown rust (Puccinia dispersa) and one of wheat brown rust (Puccinia triticina), and one race of stem rust (Puccinia graminis).

TABLE 4

The influence of individual rye chromosomes on the disease resistance of Holdfast wheat

\begin{tabular}{|c|c|c|c|c|c|c|}
\hline \multirow{2}{*}{ Host } & \multicolumn{2}{|c|}{ Rye pathogens } & \multicolumn{4}{|c|}{ Wheat pathogens } \\
\hline & Mildew & $\begin{array}{c}\text { Brown } \\
\text { rust }\end{array}$ & Mildew & $\begin{array}{c}\text { Brown } \\
\text { rust }\end{array}$ & $\begin{array}{l}\text { Yellow } \\
\text { rust }\end{array}$ & $\begin{array}{l}\text { Stem } \\
\text { rust }\end{array}$ \\
\hline $\begin{array}{l}\text { Rye } \\
\text { Wheat }\end{array}$ & $\begin{array}{c}s \\
r r\end{array}$ & $\begin{array}{c}s \\
r r\end{array}$ & $\begin{array}{c}r r \\
s\end{array}$ & $\begin{array}{c}r r \\
s\end{array}$ & $\begin{array}{c}r r \\
s\end{array}$ & $\begin{array}{l}r \\
s\end{array}$ \\
\hline $\begin{array}{l}\text { Rye-wheat } \\
\text { amphidiploid }\end{array}$ & $r r$ & $r r$ & $r$ & $s$ & $r r$ & $s$ \\
\hline $\begin{array}{l}\text { I. Addition } \\
\text { II. Addition } \\
\text { III. Addition } \\
\text { IV. Addition }\end{array}$ & $\begin{array}{l}r r \\
r r \\
r r \\
r r\end{array}$ & $\begin{array}{l}r r \\
r r \\
r r \\
r r\end{array}$ & $\begin{array}{l}s \\
r \\
r \\
s\end{array}$ & $\begin{array}{l}s \\
s \\
s \\
s\end{array}$ & $\begin{array}{l}s \\
r \\
s \\
s\end{array}$ & $\begin{array}{l}s \\
s \\
s \\
s\end{array}$ \\
\hline
\end{tabular}

\section{Chromosome 1}

The leaves of plants disomic for the addition of rye chromosome I are very pale green in colour, and the early growth rate is faster than that of Holdfast. The ears considerably exceed the length of Holdfast ears, but generally have no more spikelets and so are much more lax, especially at the base. Plants with this chromosome either monosomic or disomic have pubescent peduncles, like rye, the hairs being of about the same length and density as in rye. This "hairy-neck" character is the best marker for the chromosome. The grain is similar to that of Holdfast in shape and colour, although the ends are rather more pointed. Disomic additions reacted like Holdfast to the diseases with which they were tested.

\section{Chromosome II}

Plants disonic for the addition of rye chromosome II are faster growing in the juvenile stages than Holdfast. They have a more erect habit and shorter, broader, dark green leaves which are held stiffly upright.

The ears of this addition are longer but of about the same density as those of Holdfast, and are more tapering. The apical points of the glumes are blunter than in Holdfast but the lemma points are longer especially towards the apex of the ear. Sometimes there is a slight downiness of the peduncle in this addition, but the expression of the character is irregular, so that hairy and glabrous peduncles may 
occur on different ears of the same plant. The grain is smaller and of less regular conformation than that of the wheat parent, and is of a dark red colour which contrasts strongly with the pale colouring of Holdfast.

Additions of II are resistant to yellow rust of wheat and very resistant to wheat mildew, but like Holdfast they are susceptible to wheat stem rust and brown rust. However, no susceptibility to rye mildew or brown rust is introduced.

\section{Chromosome III}

Disomic additions of rye chromosome III have a very prostrate juvenile habit and a marked increase in tillering compared with Holdfast. However, they are most readily distinguished at this time by their extremely narrow leaves which are only about half the width of the leaves of Holdfast. The culms are also very slender and weak, although the leaves and culms of monosomic additions are not so narrow as in disomic additions. Chromosome III additions are late maturing and at maturity are very tall, being about one and a quarter times the height of Holdfast. When the ears are ripe the straw is dark red, due to anthocyanin deposits.

The ears of disomic additions, which are longer than those of Holdfast, are very slender partly as a result of the extremely low fertility, for the spikelets are not inflated as in a normal spikelet by the swelling of grain. Monosomic additions have broader ears than disomic additions, for in monosomic additions fertility is almost normal. The glumes are very stiff in disomics due to the presence of a pronounced keel, and they are longer and narrower than in Holdfast, with a narrow shoulder raised into a secondary apical tooth. The grains are narrow and elliptical in shape.

The most marked influence of this chromosome is in reducing the width and to some extent increasing the length of many organs, so that it apparently carries genes which profoundly influence the pattern of derelopment in most parts of the organism.

The disease reactions of the chromosome III additions differ from the reactions of Holdfast only in the occurrence of very considcrable resistance to wheat mildew.

\section{Chromosome IV}

Mature plants disomic for the addition of rye chromosome IV are a good deal taller than Holdfast and have very robust straw, but there are no other vegetative differences.

The ears are much longer than the ears of Holdfast, in addition they taper considerably and are very lax, especially at the base. Some of the basal spikelets are often replaced by short branches which may themselves have as many as six fertile spikelets. Branches are not developed on all the ears of a plant, and some plants may not have any, or may instead have supernumerary spikelets. That is, two spikelets may be produced one above the other at the same node, and this may happen at a number of the lower nodes of the ear. Neither supernumerary spikelets nor branches have been observed in the ears of monosomic additions. Normal spikelets in these additions are larger than in Holdfast and this, combined with the marked laxness, gives the ears a coarse appearance. The grains are shorter and flatter, and are incompletely filled and so more irregular in conformation than the grains of Holdfast. Whilst the grain is red in colour, the pigmentation is not developed to the extent that it is in chromosome II additions.

This addition does not differ from the wheat parent in disease resistance.

It should be emphasised that these addition lines were derived from one amphidiploid, which arose from one rye gamete. Thus only one genetic arrangement of each chromosome has been sampled from a population which, in an outbreeding species such as rye, may be expected to vary considerably. Therefore other addition lines founded on rye chromosomes homologous with those added in the 
present work may be phenotypically different. However, the basic genetic architecture of each representative of a particular rye chromosome must be similar, and each must make a constant and characteristic contribution to the fundamental phenotype of rye. So that it is unlikely that there would be great differences between separate addition lines for homologous rye chromosomes, against the same wheat background.

Most modifications of the wheat phenotype derive from interactions between wheat genes and rye genes. Differences between the genotypes of different recipient varieties, therefore, may alter the phenotypes of addition lines founded on them. Again, however, such variation between lines may be of a minor nature since the overall genotype of different wheat varieties must be very similar, for all produce the phenotype called $T$. vulgare.

Nevertheless the variations amongst rye addition lines due to the combination of different rye chromosomes with a range of different recipient genotypes may provide an array of material of interest to the plant breeder.

\section{THE MORPHOLOGY OF THE ADDED RYE CHROMOSOME}

The morphology of the particular rye chromosome present in each addition line is best observed at first anaphase of meiosis in monosomic additions. Since at meiosis in monosomics the rye chromosome is a univalent, and invariably lags at first anaphase. Subsequently, when the wheat chromosomes are grouped at the poles, the rye chromosome divides into its chromatid halves to reveal the structure of each chromatid stretched by the forces of movement. Detailed comparisons of the structure of chromosomes cannot be made on this evidence because stretching tensions may vary, but general comparisons seem valid. Some of the structure of the alien univalent may also be seen at first metaphase of meiosis in monosomic additions.

TABLE 5

The morphology of the added rye chromosome

\begin{tabular}{|c|c|c|}
\hline I. Chromosome & Description \\
\hline II . & $\cdot .+$ & $\begin{array}{c}\text { There is one short arm and one extremely long arm with a } \\
\text { secondary constriction, best seen at MI, mid-way along it } \\
\text { One arm is more than twice the length of the other. The } \\
\text { short arm has a pronounced secondary constriction which } \\
\text { marks off a large satellite } \\
\text { Both arms are of more or less equal lengths } \\
\text { The arms are of unequal lengths and the shorter one carries } \\
\text { a small terminal satellite. IV can be distinguished from } \\
\text { II by the greater length of the short arm relative to the } \\
\text { long arm, and by the smallness of the satellite }\end{array}$ \\
\hline
\end{tabular}

Each of the four rye chromosomes separately added to wheat may be readily distinguished from the others morphologically (plate II, table 5). Although chromosomes II and IV are similar in having 
unequal arms and satellites on their shorter arms they are readily distinguished because of the smallness of the satellite of IV, and the greater length of the long relative to the short arm of II. Some preparations of somatic nuclei of rye (plate II, fig. 6) show one pair of chromosomes with large satellites, presumably chromosome II, and two pairs with small satellites, one of these being chromosome IV. The small satellites are not always readily seen in mitotic preparations, but Levan (1942) was sometimes able to reveal three, or rarely four, satellited chromosomes in haploid rye. The small satellites may well be the larger terminal knob formations described from rye pachytene by Lima-de-Faria (1952).

Chromosome III, with roughly equal arms, cannot be related to any particular pair of the three with this structure which may be seen at mitotic metaphases.

Rye chromosome I which O'Mara (195I) added to wheat had at first metaphase of meiosis a median constriction in the form of an isthmus separating equal arms. However, the appearance of the chromosome at first anaphase of meiosis, and the nature of its telocentric derivatives, demonstrated that the centromere was in fact distal and the arms of very unequal lengths. The median constriction obvious at first metaphase was a secondary constriction, and was still apparent in telocentrics of the long arm. O'Mara demonstrated, from plants with telocentrics of each arm separately added, that a gene, or gene complex, for the hairy-neck character of rye was carried on the long arm of chromosome I.

O'Mara's observations on the morphology of chromosome I and, repeating the use of plants with telocentrics, the location of the hairyneck gene have been confirmed in detail in the present material (plate II, fig. I). There can be no doubt therefore that such a chromosome can be obtained from rye, but it is curiously difficult to demonstrate a chromosome with the morphology of I at mitotic metaphase in rye. This may be because, as at first metaphase in monosomic additions, the more or less median secondary constriction is prominent, whereas the distal centromere constriction is inconspicuous. However, a heterobrachial chromosome, not unlike chromosome I has been described from pachytene studies by Lima-de-Faria (1952), although it is not apparent from this that there is a median secondary constriction in the long arm.

From the four examples described it is evident that the morphology of the rye chromosome, as seen in monosomic additions, is a useful aid in the separation and isolation of addition lines. Thus genetic effects may be related to particular rye chromosomes, so that some analysis of the gene content of individual rye chromosomes becomes possible.

\section{DISCUSSION}

Wheat-rye derivatives are probably as amenable for the study of alien chomosome transfer as any other plant material, and it is a 
straightforward matter to add single pairs of rye chromosomes to the full complement of wheat. Each of the four rye chromosomes so added produces a characteristic alteration to the phenotype of wheat. The additional chromosome may therefore be recognised by its phenotypic effect, but it can also be distinguished by the morphology of the chromosome as seen at first anaphase of meiosis in monosomic addition.

Most of the phenotypic modifications caused by the rye chromosomes are of a quantitative nature constituting alterations to the size or rate of development of organs. There are, however, a few qualitative effects resulting in expressions entirely novel to the recipient variety. Amongst these only one, the introduction of the "hairy-neck" character, results in the development of one of the diagnostic characters which principally distinguish rye from wheat. None of the other characters which are taxonomically important in rye-the very narrow single-nerved glume, the long hairs on the keel of the lemma, exposed grain and the absence of a distinctive terminal spikelet-are introduced by the rye chromosomes examined. It seems probable that the nonhairiness of the peduncle of wheat is subject to no positive genetic control, so that in the presence of a rye gene, or gene complex, promoting the development of hairs, there are no antagonistic wheat genes. However, the other diagnostic characters are probably subject to direct control in wheat. For it is reasonable to suppose that the wheat genotype is organised to control the form and orientation of the terminal spikelet and the width of the glume, and so on. Further, the effective wheat genes, together with their intact arrays of modifiers, are epistatic to the rye genes, on isolated chromosomes, controlling the alternative expression of the character.

Other qualitative modifications of the phenotype of Holdfast are also due to the direct transfer of characteristics of rye. These are the introduction of resistance to wheat mildew, by chromosomes II and III, and wheat yellow rust by chromosome II ; and the introduction of the purple straw character by chromosomes III and IV.

The presence of at least two genes which cause the development of resistance to wheat mildew calls for comment. Rye is immune to wheat mildew, but the genetic system controlling immunity is incompletely epistatic to that responsible for susceptibility in wheat, since the wheat-rye amphidiploid shows resistance, not immunity. The display of resistance rather than immunity by the addition lines, therefore, need not be interpreted as evidence of the additive effects of the two genes to produce immunity in rye. Although the simultaneous selection of both genes is readily comprehensible on such a hypothesis.

If, however, each gene alone could produce immunity, the ultimate phenotype, in rye, then the problem of their simultaneous selection and fixation in the same genotype is raised. This situation may have arisen either by the two genes having originated in isolation and 
been brought together by crossing, or from the simultaneous selection of both genes due to their conferring resistance to different, though overlapping, ranges of races of the pathogen. Alternatively one, or both, of the genetic systems which confer mildew resistance may not be favoured by natural selection, in rye, for its disease resistance properties. The resistance which is displayed in the addition lines may merely be a side-effect of the modification of some synthesis not directly related, through selection, to disease resistance. Indeed the two host species may have diverged to such an extent over the whole range of their physiology that a single form of the pathogen is no longer sufficiently flexible to attack both. Specialisation of the pathogen might then preclude the possibility of its attacking the alternative host, so there would be no selection for resistance. No specialised system of resistance could therefore be transferred with any rye chromosome, but the modification of physiological processes might lead fortuitously to the development of resistance in addition lines.

Amongst the qualitative effects derived from interactions between rye and wheat genes are the development of red grains by chromosome II and IV additions, and the occurrence of branched ears, or supernumerary spikelets, in chromosome IV additions. The latter is particularly interesting because of its variable expression, occurring as it does in a genetically uniform addition line. All the ears of an individual are never similarly affected by branching or supernumerary formation, and the extent to which branches or supernumeraries are developed varies from plant to plant, and from year to year. The end-product of the genetic system responsible for the ear type in chromosome IV additions is thus apparently extremely sensitive to environmental variation.

This resembles the behaviour of the $F_{1}$ in a cross between forms of Triticum vulgare with normal ears and Triticum turgidum with branched ears, described by Sharman (1944). When given short days and low temperature $T$. vulgare could develop branched ears, whereas given long days and high temperatures $T$. turgidum could develop normal heads. However, over the great range of sowing conditions suitable to either parent both were developmentally stable. The species hybrid varied between individuals and between different ears of the same individual when subjected to a range of normal sowing conditions. Thus the developmental homeostasis of $T$. vulgare and $T$. turgidum depended on the genetical determination of the threshold of physiological response, but the threshold of each was at opposite extremes of the environmental range. In the $F_{1}$ the point of response became intermediate in the environmental range so that developmental stability in normal environments was lost. The genetic control of stability in normal environments had probably, as Mather (1953) has proposed, been built into the parental genotypes by selection, very likely through the selection of polygenes. Certainly the control. 
of stability of the hybrid was disturbed in a way easily understood in terms of the intermediate expression in $F_{1}$ 's, of characters dependent on many genes. It seems reasonable, incidentally, to refer to variations in ear type as developmental instability (Mather, 1953) that is nonadaptive, rather than developmental flexibility (Thoday, 1953) that is adaptive, since the latter implies exposure to selection in environments at which the different expressions of the character are produced.

The situation in rye chromosome IV addition lines differs from that in Sharman's wheat hybrid in that neither parent of the addition derivative exhibited the branching character. The novel genetic system causing the expression must therefore depend on interactions which are environmentally sensitive. The instability of a character dependent on the interaction of wheat and rye genes can be understood in relation to the instability of organisms in which the selected gene-balance has been disorganised by interference with the breeding system (Mather, I953; Jinks and Mather, I955), or by wide crossing as in the $T$. vulgare $\times T$. turgidum example. The distinction being that instead of disrupting a genotype already adjusted by natural selection to maintain developmental stability, in the addition line there had been no opportunity for selection to make the adjustments. This resembles the instability of characters dependent on newly arisen mutants (Waddington, I942).

The most marked effects of the disomic addition of rye chromosomes to wheat is on quantitative characters such as are normally considered to be subject to the control of many genes. Each of the four addition lines differs from wheat in height and straw thickness, in the size and density of ears, in the shape of spikelets and grains, and some lines in the breadth and length of leaves. Moreover the addition lines also differ from each other in these ways. Each chromosome then produces a distinctive change in quantitative characters, and the changes produced by different chromosomes are not always in the same direction. Thus the leaves of II additions are much broader and shorter than those of Holdfast, whereas the leaves of III additions are considerably longer and narrower than those of Holdfast. The genes causing the modification in the size of organs, no doubt in interaction with wheat genes, are not therefore distributed at random amongst the rye chromosomes.

The presence of some rye chromosomes produces changes in a similar direction in a wide range of characters, as in the narrowing of all the organs in III additions, whereas other chromosomes alter the dimensions of only a limited number of organs, as in the increased width of leaves and culms only in addition II, and the increase in culm width only in IV additions. Thus one rye chromosome has genes which produce similar quantitative effects throughout the plant, whereas genes in other chromosomes operate only in particular organs. A striking similarity in effect of each of the four chromosomes added is in the laxness of the ears of each addition line. Internode 
length in the ears is thus increased, although the internode length in rye ears is considerably less than that of Holdfast ears. Therefore neither the rye genes nor the wheat genes, responsible for ear density, produce their normal effects.

The sum of the quantitative and qualitative effects of each rye chromosome results in a marked modification of the phenotype of the wheat to which they have been separately added. It is perhaps surprising that an additional rye pair can produce such an effect in the presence of 2 I pairs of wheat chromosomes. However, each rye pair should probably be regarded as a seventh of a completely autonomous genotype, rather than the strict equivalent of a wheat pair. Further, the degree of alteration no doubt reflects the delicate balance attained in the wheat genotype in its selective adjustment to produce a particular phenotype. The phenotypic modifications resulting from the addition of alien chromosomes make study of this type of material potentially valuable in plant breeding, especially since it is possible to introduce such characters as disease resistance. Nevertheless, the value of this material to the plant breeder depends not only on the genetic variation made available but also on its fertility and genetic stability. These aspects of the behaviour of the present material will be considered subsequently.

\section{SUMMARY}

I. Four pairs of rye chromosomes were separately added to the full complement of 42 wheat chromosomes to produce 44 -chromosome addition lines. The single pair transfers were made by a sequence of crosses and selfings in the derivatives of wheat-rye hybrids. Such transfers are required if rye characters are to be incorporated in wheat since there is no pairing between the chromosomes of rye and wheat.

2. Each rye pair produces a marked and distinctive modification of the phenotype of the wheat variety to which it is added. Most modifications are in quantitative characters, although there are qualitative changes some of which, such as the introduction of disease resistance, are potentially valuable in wheat improvement.

3. Different addition lines may be recognised not only by their phenotypes but also by the morphology of the rye chromosome as seen at first anaphase of meiosis in monosomic additions.

4. The isolation of single chromosomes of rye against the wheat genotype provides genetical information about rye, and enables genetic effects to be related to particular chromosomes, in a way not possible working with euploids.

Acknowledgment.- It is a pleasure to acknowledge the interest and encouragement of Dr G. D. H. Bell in the course of this work. 


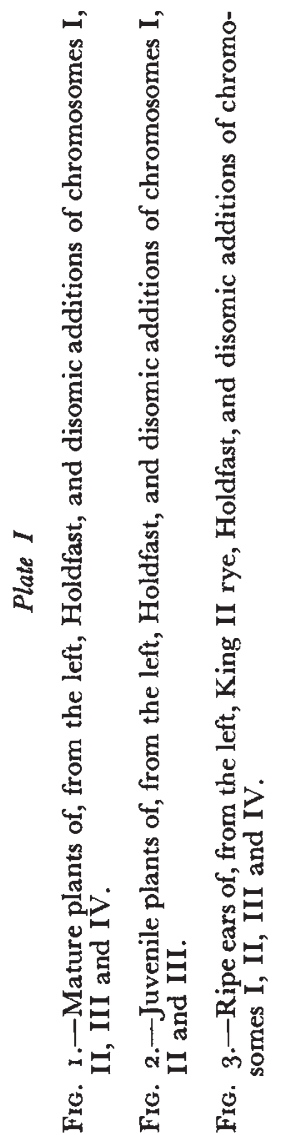




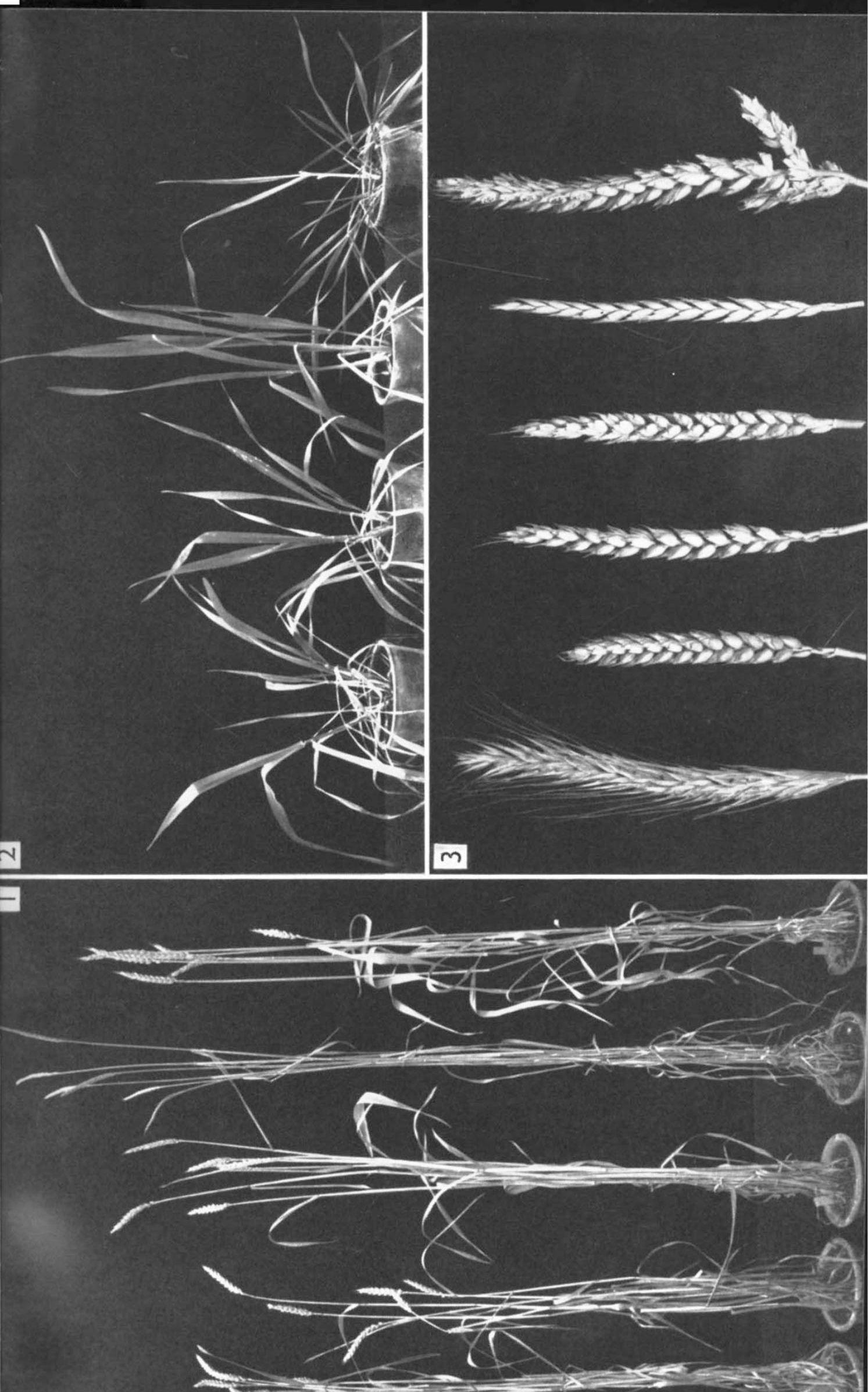


Plate II

Fig. I,-Chromosome I. Fig. 2,-Chromosome II. Fig, 3,--Chromosome III. Fig. 4.Chromosome IV, shown as univalents dividing into their chromatid halves at first anaphase of meiosis in 43-chromosome monosomic addition plants. $\times 2200$.

FIG. 5.-Mitotic metaphase from a root-tip of King II rye fixed after 24 hours at $0-2^{\circ} \mathrm{C}$. $\times 2600$. 


\section{REFERENCES}

BELl, (.. D. H., LUPTON, M., AND RILEy, R. 1955. Investigations in the Triticinæ. III. The morphology and field behaviour of the $A_{2}$ generation of interspecific and intergeneric amphidiploids. 7. Agric. Sci., 46, 199-231.

blakf.slee, A. F. 1934. New jimison weeds from old chromosomes. J. Hered., $2.5,8 \mathrm{I}-\mathrm{I} 08$.

BLAKFSI,Ee, A. F., AND AVERY, A. G. 1934. Three genes located in the 21.22 chromosome of the jimson weed. .7. Hered., 2.5, 393-404.

Chapman, v., AND RILEY, R. I955. The disomic addition of rye chromosome II to wheat. Nature, Lond., $175, \mathrm{I}$ ing $\mathrm{I}$.

(jERSTEL, D. V. 1945. Inheritance in Nicotiana tobacum. XX. The addition of Nicotiana glutenosa chromosomes to tobacco. J. Hered., 36, 197-206.

HYDE, B. B. 1953. Addition of individual Haynaldia villosa chromosomes to hexaploid wheat. Amer. 7. Bot., 4G, I 74-1 82 .

JiNKS, J. L., AND MATHER, K. 1955. Stability in development of heterozygotes and homozygotes. P.R.S., B, ${ }_{4} 43,56 \mathrm{I}-528$.

LEVAN, A. 1942. Studies on the meiotic mechanism of haploid rye. Hereditas, $28,177-211$.

LIMA-DE-FARIA, A. 1952. The chromomere analysis of the chromosome complement of rye. Chromosoma, $5, \mathrm{I}-68$.

LINDSCHAU, M., AND OEHLER, E. 1935. Untersuchungen am Konstant intermediären additiven Rimpauschen Weizen-Roggen-bastard. Züchter, 7, 228-233.

mather, K. 1953. Genetical control of stability in development. Heredity, 7, 297-336.

MÜNTZING, A. 1939. Studies on the properties and ways of production of ryewheat amphidiploids. Hereditus, 25, 387-430.

MÜNTZING, A. 1948. Fxperiences from work with induced polyploidy in cereals. Svalöf ı 886-1946 (ed. Å. Åkerman, O. Tedin and K. Fröier), pp. 324-337.

o'ntara, J. G. I940. Cytogenetic studies on Triticale. I. A method for determining, the effects of individual Secale chromosomes on Triticum. Genetics, 25, 401-408.

o'mara, J. G. I95I. Cytogenetic studies in Triticale. II. The kinds of intergeneric chromosome additions. Cytologia, $16,225-232$.

RILEY, R., AND CHAPMAN, v. 1957. The comparison of wheat-rye and wheatAgilops amphidiploids. 3. Agric. Sci., 49, 246-250.

RIMPAU, W. I891. Kreuzungsprodukte landwirtsohafrliche Kulturpflanze. Landwirt Jahrb., 20, 335-371.

SEARS, E. R. I 954 . The aneuploids of common wheat. Res. Bull. Mo. Agric. Sta., no. 572 .

SEARS, E. R. 1956. The transfer of leaf-bunt resistance from Agilops umbellulata to wheat. Brookhaven Symposia in Biology, 9, I-22.

SHARMAN, B. C. 1944. Branched heads in wheat and wheat hybrids. Nature, Lond., ${ }^{153}, 497$.

THoday, J. M. 1953. Components of fitness. Symp. Soc. Exp. Biol., 7, 96-1 13.

WADDINGTON, C. H. 1942. Canalisation of development in the inheritance of acquired characters. Nature, Lond., ${ }^{150}, 563-565$. 